\title{
Early and long-term outcomes of coronary artery bypass grafting in patients with acute coronary syndrome versus stable angina pectoris
}

\author{
Toshihiro Fukui, MD, ${ }^{\mathrm{a}}$ Minoru Tabata, MD, MPH, ${ }^{\mathrm{a}}$ Satoshi Morita, MD, $\mathrm{PhD},{ }^{\mathrm{b}}$ and \\ Shuichiro Takanashi, MD ${ }^{\mathrm{a}}$
}

Objectives: The aim of the present study was to determine the early and long-term outcomes of coronary artery bypass grafting in patients with acute coronary syndrome and stable angina pectoris.

Methods: From September 2004 to September 2011, 382 patients with acute coronary syndrome (unstable angina pectoris and non-ST-segment elevation myocardial infarction) and 851 patients with stable angina pectoris underwent first-time isolated coronary artery bypass grafting at our institute. The early and long-term outcomes were compared between the 2 groups.

\begin{abstract}
Results: Patients with acute coronary syndrome were older, were more likely to be women, had a smaller body surface area, and were more likely to have left main coronary artery disease. In both groups, bilateral internal thoracic artery grafts were used in approximately $89 \%$ of the patients, and off-pump techniques in approximately $97 \%$ of the patients. The acute coronary syndrome group had a greater operative death rate $(2.6 \% \mathrm{vs} 0.1 \%)$ and a greater incidence of low output syndrome $(3.1 \%$ vs $1.2 \%)$ and hemodialysis requirement $(2.9 \%$ vs $1.1 \%)$. Multivariate regression analysis demonstrated that age, acute coronary syndrome, lower ejection fraction, and higher creatinine level before surgery were independent predictors of operative death. However, among the hospital survivors, no differences were seen in freedom from all death $(85.4 \% \pm 2.5 \%$ vs $87.7 \% \pm 2.0 \%)$, cardiac death $(97.4 \% \pm 0.9 \%$ vs $96.5 \% \pm 0.9 \%)$, or major adverse cardiac and cerebrovascular events $(78.0 \% \pm 2.9 \%$ vs $78.1 \% \pm 2.3 \%$ ) at 7 years between the patients with acute coronary syndrome and stable angina pectoris.
\end{abstract}

Conclusions: Although acute coronary syndrome is an independent predictor of early mortality in patients undergoing coronary artery bypass grafting, the long-term outcomes after surgery were similar between patients with acute coronary syndrome and stable angina pectoris who survived the early postoperative period. (J Thorac Cardiovasc Surg 2013;145:1577-83)

\section{Supplemental material is available online.}

Acute coronary syndrome (ACS) is one of the leading causes of morbidity and mortality in patients with coronary artery disease. Technological advances have resulted in the widespread use of percutaneous coronary intervention (PCI), which has improved the results of ACS treatment. In patients with ST-segment elevation myocardial infarction (STEMI), primary PCI is recommended, if immediately available. ${ }^{1}$ In patients with unstable angina pectoris (UAP) or non-STEMI, either PCI or coronary artery bypass grafting $(\mathrm{CABG})$ could be recommended, depending on the

From the Department of Cardiovascular Surgery, ${ }^{\mathrm{a}}$ Sakakibara Heart Institute, Tokyo, Japan; and Department of Biostatistics and Epidemiology, ${ }^{\mathrm{b}}$ Yokohama City University Medical Center, Yokohama, Japan.

Disclosures: Authors have nothing to disclose with regard to commercial support. Received for publication Feb 19, 2012; revisions received April 20, 2012; accepted for publication May 16, 2012; available ahead of print June 18, 2012.

Address for reprints: Toshihiro Fukui, MD, Department of Cardiovascular Surgery,

Sakakibara Heart Institute, 3-16-1 Asahi-cho, Fuchu City, Tokyo 183-0003, Japan

(E-mail: tfukui.cvs@gmail.com).

$0022-5223 / \$ 36.00$

Copyright (C) 2013 by The American Association for Thoracic Surgery

doi:10.1016/j.jtcvs.2012.05.043 patient characteristics and coronary lesion. ${ }^{2}$ Recent trends in patients undergoing $\mathrm{CABG}$ have shown an increase in the number of patients with left main coronary artery disease, preoperative use of the intra-aortic balloon pump, and urgent cases, ${ }^{3}$ demonstrating that $\mathrm{CABG}$ remains the treatment of choice for patients with complex coronary artery disease and high-risk factors. ${ }^{4}$

Although ACS has historically been considered a risk factor in patients undergoing $\mathrm{CABG}$, with several reports of adverse outcomes, ${ }^{5}$ recent advances in techniques and technology (eg, arterial grafts, off-pump CABG, and minimally invasive cardiopulmonary bypass) have improved the outcomes of patients with ACS who undergo CABG. ${ }^{6,7}$ However, few reports have evaluated the early and longterm outcomes of patients with ACS and stable angina pectoris (SAP) who underwent these contemporary surgical modalities. ${ }^{8,9}$

The aim of the present study was to compare the early and long-term outcomes after contemporary CABG between patients with ACS and those with SAP.

\section{METHODS}

\section{Study Patients}

From September 2004 to September 2011, 1303 patients underwent first-time isolated CABG at Sakakibara Heart Institute. Of these, 70 patients 


$$
\begin{aligned}
& \text { Abbreviations and Acronyms } \\
& \begin{aligned}
\text { ACS } & =\text { acute coronary syndrome } \\
\text { CABG } & =\text { coronary artery bypass grafting } \\
\text { ITA } & =\text { internal thoracic artery } \\
\text { MACCE } & =\text { major adverse cardiac and } \\
& \text { cerebrovascular events } \\
\text { PCI } & =\text { percutaneous coronary intervention } \\
\text { SAP } & =\text { stable angina pectoris } \\
\text { STEMI } & =\text { ST-segment elevation myocardial } \\
& \text { infarction } \\
\text { UAP } & \text { unstable angina pectoris }
\end{aligned}
\end{aligned}
$$

with STEMI (see Tables E1 and E2) were excluded from the present study because the treatment strategies for patients with STEMI are complex and differ from those for other patients. The remaining 1233 patients were included in the present study. The preoperative characteristics of the study patients are listed in Table 1. The preoperative diagnosis was ACS in 382 patients $(31.0 \%$; UAP in 360 and non-STEMI in 22) and SAP in 851 patients $(69.0 \%)$. Myocardial infarction was diagnosed from the electrocardiographic findings and serum cardiac enzyme levels, and the location of culprit lesion was confirmed using coronary angiography.

Patients with ACS were initially treated with aspirin, $\beta$-blockers, and antithrombin therapy. All patients with ACS underwent angiography early after the start of medication. After angiography, primary PCI was performed when the coronary artery disease was suitable for PCI. Even if the patients had triple-vessel disease, only the culprit lesion was treated with PCI, when possible. Those patients underwent staged CABG after primary PCI. However, those patients were few in the present study $(n=9)$. Because they were converted from ACS to SAP at CABG, they were included in the SAP group in the present study. The other patients with ACS underwent early CABG. Our CABG strategy for ACS, including STEMI, non-STEMI, and UAP, is shown in Figure E1.

The institutional review board approved the present retrospective study and waived the need for written consent. We compared the preoperative, intraoperative, and postoperative variables between the patients with ACS and SAP. Multivariate logistic regression analysis was performed to determine the significant predictors of operative death and major complications. The long-term outcomes were compared between the 2 groups. All data were collected prospectively and reviewed retrospectively.

The primary endpoint of the present study was early all-cause mortality. The secondary endpoints were (1) early morbidity, including re-exploration because of bleeding, low output syndrome, perioperative myocardial infarction, severe ventricular arrhythmia, requirement of hemodialysis, stroke, or mediastinitis; (2) long-term all-cause mortality, excluding early deaths; (3) late cardiac death; and (4) late major adverse cardiac and cerebrovascular events (MACCE).

\section{Surgery}

Our strategy for isolated $\mathrm{CABG}$ was directed at achieving complete myocardial revascularization with an off-pump technique, whenever feasible. Complete revascularization was defined as "traditional" completeness, indicating that all diseased arterial systems (stenosis $>50 \%$ ) received at least 1 graft. The off-pump CABG technique has been previously described. ${ }^{10}$ We bypassed all significantly diseased coronary arteries (stenosis $\geq 50 \%$ ) that were greater than $1 \mathrm{~mm}$ in diameter. If necessary, concomitant extensive reconstruction (length, $\geq 4.0 \mathrm{~cm}$ ) with or without endarterectomy was performed in patients with a diffusely diseased left anterior descending artery. ${ }^{11}$ Deep pericardial stay sutures were not used, and a commercially available heart positioner and stabilizer were applied in all cases. Cardiopulmonary bypass with or without cardiac arrest was used in patients who were not suitable for the off-pump technique, including patients with severely impaired left ventricular function or intramyocardial coronary arteries.

Bypass grafts were prepared after heparinization (300 IU/kg). Arterial grafts (internal thoracic artery [ITA], radial artery, and gastroepiploic artery) were harvested in a skeletonized fashion. Anastomoses between the coronary arteries and grafts were performed with 8-0 polypropylene running sutures using the parachute technique.

We routinely prescribed low-dose aspirin for all postoperative patients, continued indefinitely. Warfarin (maintained with a target international normalized ratio of 2.0) was administered for 3 months for patients with saphenous vein grafts, in addition to low-dose aspirin.

Follow-up was achieved by outpatient office visits, direct communication with the patient or family, and/or reports from the family physicians. The last follow-up examination was completed in all patients during a 1-month closing interval ending in December 2011.

\section{Definitions}

UAP was defined as chest pain at rest that was of new onset or that was increasing in frequency and severity. SAP was defined as chest pain on exertion that was relieved by rest or medication. Left main coronary artery disease was defined as the presence of $50 \%$ or greater stenosis on any angiographic view, according to the Society of Thoracic Surgeons database.

Operative death was defined as death within the same hospitalization or within 30 days of surgery. Cardiac death included all deaths from any cardiac cause (acute myocardial infarction, heart failure, or arrhythmia) and sudden unexplained deaths. Low-output syndrome was defined as the need for adrenaline, more than $5 \mu \mathrm{g} / \mathrm{kg} / \mathrm{min}$ dopamine or dobutamine, or intraaortic balloon pumping. Perioperative myocardial infarction was defined as new $\mathrm{Q}$ waves on the electrocardiogram or a peak creatine kinase-MB level 5 times or more the upper limit of normal (25 IU/L). Respiratory failure was defined as a requirement for prolonged ventilation ( $>48$ hours) or the occurrence of pneumonia. Postoperative stroke was defined as the occurrence of a new stroke confirmed by computed tomography. In patients with preoperative stroke, postoperative stroke was defined as a worsening of the neurologic deficit with new radiologic findings. MACCE was defined as death from any cause, stroke, myocardial infarction, or repeat revascularization.

\section{Statistical Analysis}

All statistical analyses were performed using the StatView, version 5.0, software package or the SAS program for Windows, release 9.2 (SAS Institute, Cary, NC). Continuous variables are reported as the mean \pm standard deviation. Continuous variables were compared using the Student $t$ test, and discrete variables were compared using the chi-square or Fischer exact test.

Univariate and multivariate logistic regression analyses were performed to determine the significant predictors of operative death and major morbidity. The variables used for univariate analysis were the clinical variables listed in Table 1, in addition to ACS and SAP and bilateral ITA use. Variables with $P<.1$ on univariate analyses were included in the multivariate model.

Actuarial event-free survival curves were estimated using the KaplanMeier method. The log-rank test was used to assess the differences in survival between the 2 groups.

Univariate and multivariate Cox proportional hazard analyses were performed to investigate the significant predictors of late mortality, late cardiac mortality, and late MACCE. The variables used for univariate analysis were the clinical variables listed in Table 1 plus ACS, SAP, and bilateral ITA use. Variables with $P<.1$ on univariate analyses were included in the multivariate model.

A propensity score of having ACS was calculated for each patient using a logistic regression model that included all the preoperative variables listed in Table 1. Patients were matched 1 to 1 by the propensity scores 
TABLE 1. Preoperative patient characteristics

\begin{tabular}{|c|c|c|c|c|c|c|}
\hline \multirow[b]{2}{*}{ Characteristic } & \multicolumn{3}{|c|}{ Nonmatched pairs } & \multicolumn{3}{|c|}{ Propensity-matched pairs } \\
\hline & $\operatorname{ACS}(n=382)$ & $\operatorname{SAP}(\mathbf{n}=\mathbf{8 5 1})$ & $P$ value & $\operatorname{ACS}(n=342)$ & $\mathrm{SAP}(\mathrm{n}=342)$ & $P$ value \\
\hline Age (y) & $69.8 \pm 9.7$ & $67.1 \pm 10.7$ & $<.0001$ & $69.2 \pm 9.7$ & $68.8 \pm 9.2$ & .5756 \\
\hline Female gender & $104(27.2)$ & $133(15.6)$ & $<.0001$ & $78(22.8)$ & $86(25.1)$ & .5307 \\
\hline $\operatorname{BSA}\left(\mathrm{m}^{2}\right)$ & $1.6 \pm 0.2$ & $1.7 \pm 0.2$ & .0046 & $1.6 \pm 0.2$ & $1.6 \pm 0.2$ & .9206 \\
\hline $\mathrm{EF}(\%)$ & $55.7 \pm 12.3$ & $56.5 \pm 11.2$ & .2579 & $56.1 \pm 12.2$ & $55.7 \pm 11.9$ & .6366 \\
\hline Prior MI & $147(38.5)$ & $404(47.5)$ & .0040 & $141(41.2)$ & $146(42.7)$ & .7566 \\
\hline Diseased vessel & $2.7 \pm 0.5$ & $2.8 \pm 0.5$ & .1539 & $2.8 \pm 0.5$ & $2.8 \pm 0.5$ & .7433 \\
\hline Left main disease & $178(46.6)$ & $245(28.8)$ & $<.0001$ & $141(41.2)$ & 133 (38.9) & .5849 \\
\hline Previous PCI & $104(27.2)$ & $249(29.3)$ & .5075 & $99(28.9)$ & $105(30.7)$ & .6760 \\
\hline $\mathrm{CHF}$ & $51(13.4)$ & $102(12.0)$ & .5627 & $44(12.9)$ & $47(13.7)$ & .8218 \\
\hline Hypertension & $271(70.9)$ & $569(66.9)$ & .1752 & $244(71.3)$ & 239 (69.9) & .7371 \\
\hline Diabetes mellitus & $164(42.9)$ & $415(48.8)$ & .0663 & $151(44.2)$ & 149 (43.6) & .9386 \\
\hline Hyperlipidemia & $243(63.6)$ & $538(63.2)$ & .9454 & $221(64.6)$ & 221 (64.6) & $>.9999$ \\
\hline Smoking & $220(57.6)$ & $514(60.4)$ & .3864 & 204 (59.6) & $207(60.5)$ & .8759 \\
\hline PVD & $21(5.5)$ & $78(9.2)$ & .0376 & $20(5.8)$ & $26(7.6)$ & .4453 \\
\hline Previous stroke & $41(10.7)$ & $89(10.5)$ & .9641 & $37(10.8)$ & $39(11.4)$ & .9032 \\
\hline Creatinine $(\mathrm{mg} / \mathrm{dL})$ & $1.2 \pm 1.6$ & $1.2 \pm 1.4$ & .8263 & $1.2 \pm 1.6$ & $1.2 \pm 1.5$ & .7643 \\
\hline COPD & $16(4.2)$ & $29(3.4)$ & 6087 & $14(4.1)$ & $10(2.9)$ & .5330 \\
\hline Atrial fibrillation & $18(4.7)$ & $41(4.8)$ & $>.9999$ & $17(5.0)$ & $17(4.9)$ & $>.9999$ \\
\hline
\end{tabular}

Data presented as mean \pm standard deviation or numbers (percentages). $A C S$, Acute coronary syndrome; $B S A$, body surface area; $C H F$, congestive heart failure; $C O P D$, chronic obstructive pulmonary disease; $E F$, ejection fraction; $M I$, myocardial infarction; $P C I$, percutaneous coronary intervention; $P V D$, peripheral vascular disease; $S A P$, stable angina pectoris.

using the greedy matching techniques. Outcomes of interest between the matched groups were compared using the paired $t$ test for continuous variables and the McNemar test for discrete variables.

\section{RESULTS}

\section{Preoperative Characteristics and Intraoperative and Early Postoperative Outcomes}

The preoperative characteristics of the ACS and SAP groups are listed in Table 1. The patients with ACS were older, were more likely to be women, had a smaller body surface area, were more likely to have left main coronary artery disease, were less likely to have previous myocardial infarction, and were less likely to have peripheral vascular disease than those with SAP.

The intraoperative and early postoperative outcomes of both groups are listed in Table 2. The number of anastomoses per patient was lower in the ACS group than in the SAP group. No difference was seen in the frequency of ITA

TABLE 2. Operative and postoperative patient data

\begin{tabular}{|c|c|c|c|c|c|c|}
\hline \multirow[b]{2}{*}{ Variable } & \multicolumn{3}{|c|}{ Nonmatched pairs } & \multicolumn{3}{|c|}{ Propensity-matched pairs } \\
\hline & $\operatorname{ACS}(n=382)$ & SAP $(\mathbf{n}=\mathbf{8 5 1})$ & $P$ value & $\operatorname{ACS}(n=342)$ & $\operatorname{SAP}(n=342)$ & $P$ value \\
\hline Anastomoses & $4.0 \pm 1.2$ & $4.2 \pm 1.2$ & .0292 & $4.1 \pm 1.3$ & $4.2 \pm 1.3$ & .3186 \\
\hline ITA use & $381(99.7)$ & 848 (99.6) & $>.9999$ & $341(99.7)$ & $341(99.7)$ & $>.9999$ \\
\hline Bilateral ITA use & $338(88.5)$ & $754(88.6)$ & $>.9999$ & $306(89.5)$ & $304(88.9 \%$ & .9020 \\
\hline Extensive reconstruction of LAD & $71(18.6)$ & $211(24.8)$ & .0170 & $69(20.2)$ & $77(22.5)$ & .5136 \\
\hline Off-pump procedure & $373(97.6)$ & $819(96.2)$ & .8018 & $335(98.0)$ & $329(96.2)$ & .2565 \\
\hline Operation time (min) & $264.7 \pm 62.3$ & $282.2 \pm 61.7$ & $<.0001$ & $268.2 \pm 62.9$ & $279.2 \pm 63.1$ & .0226 \\
\hline Transfusion & $177(46.3)$ & $230(27.0)$ & $<.0001$ & $149(43.6)$ & $106(31.0)$ & .0009 \\
\hline Intubation (h) & $11.8 \pm 20.3$ & $8.0 \pm 8.5$ & $<.0001$ & $11.9 \pm 21.3$ & $8.5 \pm 10.8$ & .0093 \\
\hline ICU stay $(\mathrm{d})$ & $2.6 \pm 12.5$ & $1.3 \pm 1.1$ & .0006 & $2.6 \pm 11.7$ & $1.4 \pm 1.4$ & .0511 \\
\hline Operative death & $10(2.6)$ & $1(0.1)$ & .0002 & $9(2.6)$ & $1(0.3)$ & .0258 \\
\hline Re-exploration due to bleeding & $6(1.6)$ & $8(0.9)$ & .4792 & $6(1.7)$ & $5(1.5)$ & $>.9999$ \\
\hline Low output syndrome & $12(3.1)$ & $10(1.2)$ & .0018 & $9(2.6)$ & $3(0.9)$ & .1453 \\
\hline Perioperative MI & $6(1.6)$ & $6(0.7)$ & .4164 & $8(1.5)$ & $2(0.6)$ & .4474 \\
\hline Severe ventricular arrhythmia & $3(0.8)$ & $6(0.7)$ & .2101 & $2(0.6)$ & 0 & .4789 \\
\hline Required hemodialysis & $11(2.9)$ & $9(1.1)$ & .0278 & $9(2.6)$ & $4(1.2)$ & .2627 \\
\hline Stroke & $7(1.8)$ & $10(1.2)$ & .1372 & $6(1.8)$ & $3(0.9)$ & .5022 \\
\hline Mediastinitis & $4(1.0)$ & $7(0.8)$ & .7617 & $4(1.2)$ & $4(1.2)$ & $>.9999$ \\
\hline
\end{tabular}

Data presented as mean \pm standard deviation or numbers (percentages). ACS, Acute coronary syndrome; ICU, intensive care unit; ITA, internal thoracic artery; $L A D$, left anterior descending artery; $M I$, myocardial infarction; $S A P$, stable angina pectoris. 
TABLE 3. Multivariate logistic regression analysis for operative death, low output syndrome, and hemodialysis requirement

\begin{tabular}{lrrl}
\hline \multicolumn{1}{c}{ Outcome } & \multicolumn{1}{c}{ OR } & $\boldsymbol{P}$ value & \multicolumn{1}{c}{$\mathbf{9 5} \% \mathbf{C I}$} \\
\hline Operative death & & & \\
$\quad$ Age & 1.162 & .0063 & $1.043-1.294$ \\
ACS & 16.772 & .0091 & $2.015-139.608$ \\
EF & 0.938 & .0204 & $0.889-0.990$ \\
$\quad$ Creatinine & 1.320 & .0223 & $1.040-1.676$ \\
Low output syndrome & & & \\
$\quad$ Ejection fraction & 0.933 & $<.0001$ & $0.904-0.963$ \\
$\quad$ Bilateral ITA use & 0.244 & $<.0001$ & $0.093-0.641$ \\
Required hemodialysis & & & \\
$\quad$ ACS & 2.762 & .0346 & $1.077-7.089$ \\
$\quad$ Creatinine & 1.253 & .0006 & $1.102-1.425$ \\
\hline
\end{tabular}

$A C S$, Acute coronary syndrome; $C I$, confidence interval; $E F$, ejection fraction; ITA, internal thoracic artery; $O R$, odds ratio.

grafts between the 2 groups. Most patients in the present study received bilateral ITA grafts through an off-pump procedure.

Postoperatively, the rates of operative death, low output syndrome, and hemodialysis requirement were significantly greater in the patients with ACS than in the patients with SAP. Of the patients with ACS who died, the cause of death was pneumonia in 5 , sepsis in 2 , low output syndrome in 1 , thoracic aneurysm rupture in 1 , and ischemic colitis in 1 . Of the patients with SAP, 1 patient died of low output syndrome.

\section{Risk of Operative Death}

Univariate analyses identified that age, a smaller body surface area, ACS, a lower ejection fraction, a history of congestive heart failure, hyperlipidemia, a greater creatinine level, and atrial fibrillation were associated with operative death. Multivariate analysis (Table 3 ) revealed that age, ACS, a lower ejection fraction, and a greater creatinine level were independent predictors of operative death.

\section{Risk of Postoperative Low Output Syndrome}

Univariate analyses identified that age, ACS, a lower ejection fraction, a history of congestive heart failure, hyperlipidemia, a greater creatinine level, and the use of bilateral ITA were associated with the development of low output syndrome. Multivariate analysis (Table 3) revealed that a lower ejection fraction and the use of bilateral ITA were independent predictors of low output syndrome. ACS was not identified as an independent predictor of low output syndrome (odds ratio, $1.839 ; 95 \%$ confidence interval, $0.518-6.533 ; P=.3462$ ).

\section{Risk of Postoperative Hemodialysis Requirement}

Univariate analyses identified that age, ACS, a lower ejection fraction, a history of congestive heart failure, peripheral vascular disease, and a greater creatinine level were associated with a hemodialysis requirement. Multivariate analysis (Table 3 ) revealed that ACS and greater creatinine level were independent predictors of a hemodialysis requirement.

\section{Propensity Score-Matched Pairs Analysis}

The preoperative and perioperative data of the propensity-matched patients are listed in Tables 1 and 2, respectively. These matched pairs were well balanced for all known covariates (Table 1). The operative death rate was significantly greater for patients with ACS than for patients with SAP. However, no difference was found in the incidence of postoperative complications between the 2 groups.

\section{Long-Term Postoperative Outcomes}

Follow-up was complete for 1219 (98.9\%) of 1233 patients. During the follow-up period $(44.1 \pm 24.6$ months), 36 patients with ACS died and 53 patients with SAP died (excluding operative deaths). Of the 1222 hospital survivors, the actuarial survival at 7 years was $85.4 \% \pm 2.5 \%$ for patients with ACS and $87.7 \% \pm 2.0 \%$ for patients with SAP (Figure 1, $A$ ). There were 8 cardiac deaths in patients with ACS and 18 in patients with SAP. Freedom from cardiac death at 7 years was $97.4 \% \pm 0.9 \%$ for patients with ACS and $96.5 \% \pm 0.9 \%$ for patients with SAP (Figure 1, B). Repeat revascularization was performed in 19 patients with ACS and 58 with SAP. Stroke was observed in 6 patients with ACS and 8 with SAP. Acute myocardial infarction occurred in 1 patient with ACS and 3 with SAP. Freedom from MACCE at 7 years was $78.0 \% \pm 2.9 \%$ for those with ACS and $78.1 \% \pm 2.3 \%$ for those with SAP (Figure 1, C).

\section{Risk of Late Mortality}

Univariate analyses identified that age, a smaller body surface area, a lower ejection fraction, number of diseased vessels, left main disease, a greater creatinine level, and atrial fibrillation were associated with late mortality. Multivariate analysis (Table 4) revealed that age, a smaller body surface area, a lower ejection fraction, and a greater creatinine level were independent predictors of late mortality. ACS was not identified as an independent predictor of late mortality (hazard ratio, $0.712 ; 95 \%$ confidence interval, $0.466-1.088 ; P=.1166)$.

\section{Risk of Late Cardiac Death}

Univariate analyses identified that female gender, a smaller body surface area, a lower ejection fraction, previous PCI, smoking, and a greater creatinine level were associated with late cardiac death. Multivariate analysis (Table 4) revealed that a smaller body surface area, a lower ejection fraction, previous PCI, and a greater creatinine level were independent predictors of late cardiac death. 


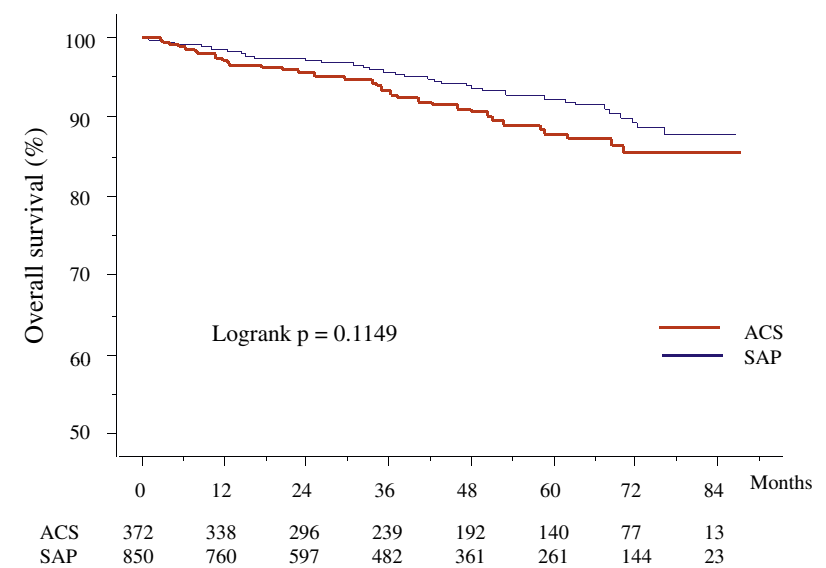

A

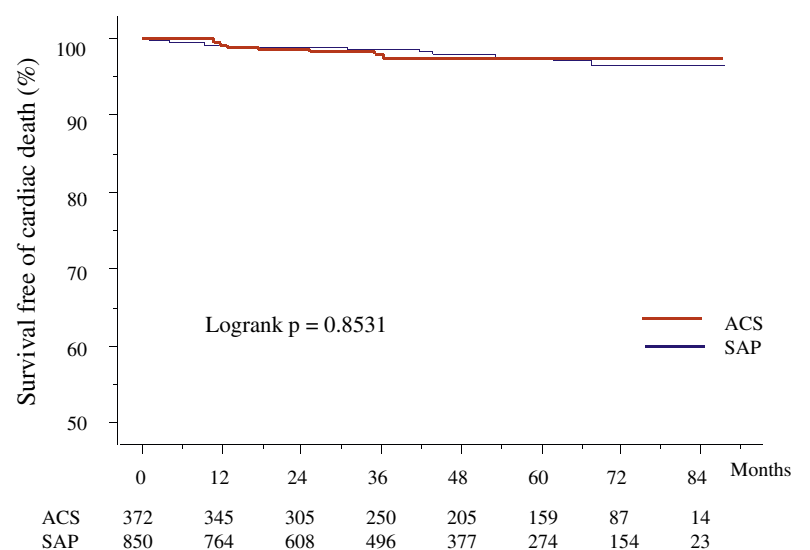

B

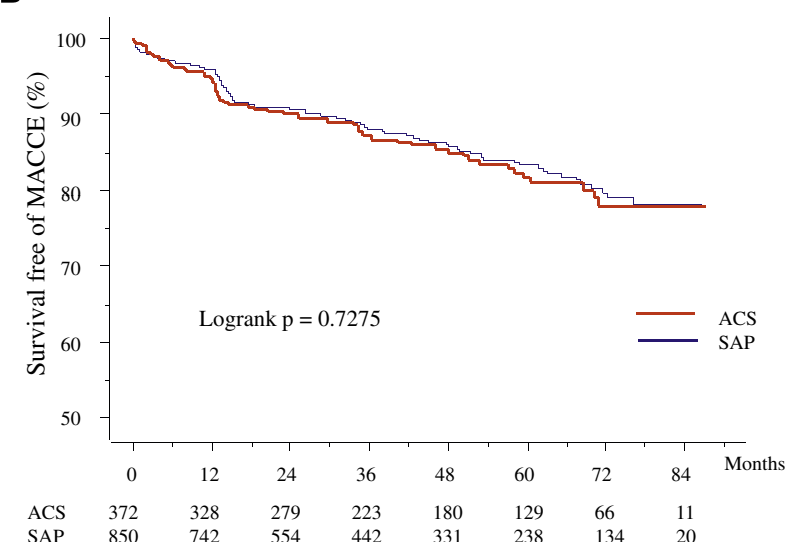

C

FIGURE 1. A, Kaplan-Meier event-free survival analysis for all-cause death. B, Kaplan-Meier event-free survival analysis for cardiac death. C, Kaplan-Meier event-free survival analysis for major adverse cardiac and cerebrovascular events (death from any cause, stroke, myocardial infarction, or repeat revascularization). ACS, Acute coronary syndrome; SAP, stable angina pectoris; $M A C C E$, major adverse cardiac and cerebrovascular events.

ACS was not identified as an independent predictor of late cardiac death (hazard ratio, 1.082; 95\% confidence interval, $0.470-2.490 ; P=.8532$ ).
TABLE 4. Multivariate Cox proportional hazard analysis for late mortality

\begin{tabular}{lrrr}
\hline \multicolumn{1}{c}{ Outcome } & HR & $\boldsymbol{P}$ value & $\mathbf{9 5 \%}$ CI \\
\hline Late mortality & & & \\
$\quad$ Age & 1.063 & $<.0001$ & $1.031-1.095$ \\
BSA & 0.166 & .0007 & $0.058-0.470$ \\
EF & 0.967 & $<.0001$ & $0.952-0.983$ \\
Creatinine & 1.198 & $<.0001$ & $1.097-1.310$ \\
Late cardiac mortality & & & \\
BSA & 0.127 & .0224 & $0.022-0.746$ \\
Ejection fraction & 0.964 & .0141 & $0.936-0.993$ \\
Previous PCI & 3.471 & .0453 & $1.027-11.737$ \\
Creatinine & 1.254 & .0004 & $1.107-1.419$ \\
Late MACCE & & & \\
BSA & 0.444 & .0496 & $0.197-0.999$ \\
EF & 0.981 & .0017 & $0.969-0.993$ \\
Creatinine & 1.096 & .0163 & $1.017-1.182$ \\
\hline BSA, Body
\end{tabular}

$B S A$, Body surface area; $C I$, confidence interval; $E F$, ejection fraction; $H R$, hazard ratio; $M A C C E$, major adverse cardiac and cerebrovascular events; $P C I$, percutaneous coronary intervention.

\section{Risk of Late MACCE}

Univariate analyses identified that age, a smaller body surface area, a lower ejection fraction, number of diseased vessels, and a greater creatinine level were associated with late MACCE. Multivariate analysis (Table 4) revealed that a smaller body surface area, a lower ejection fraction, and a greater creatinine level were independent predictors of late MACCE. ACS was not identified as an independent predictor of late MACCE (hazard ratio, $0.945 ; 95 \%$ confidence interval, $0.690-1.296 ; P=.7276$ ).

\section{DISCUSSION}

In the present study, ACS was identified as an independent predictor of operative death. Among hospital survivors, however, no difference was seen in long-term mortality between patients with ACS versus those with SAP.

Recent advances in technology have led to an increase in the proportion of patients with ACS undergoing PCI. BenGal and colleagues ${ }^{12}$ compared the early and mid-term outcomes of patients with ACS after treatment with PCI or CABG in a propensity-matched study. They found that although PCI was associated with lower rates of periprocedural stroke, major bleeding, and acute renal injury, CABG was associated with greater freedom from both early and late recurrent ischemia requiring repeat revascularization procedures. The survival at 1 month and 1 year were comparable between the groups. The selection of the optimal revascularization modality for patients with ACS depends on the patient characteristics and lesion severity. CABG is still appropriate for patients with disease refractory to medical therapy and when PCI is not suitable or possible. 
A review study by Kaiser and colleagues ${ }^{13}$ reported that the mean operative mortality rate in CABG patients with UAP was $3.7 \%$ (range, $1.2-8.8 \%$ ). In the present study, the operative death rate was significantly greater in patients with ACS than with SAP $(2.6 \%$ vs $0.1 \%)$. Bonacchi and colleagues ${ }^{9}$ did not find any difference in the operative mortality rate between patients undergoing urgent and elective CABG, but both groups in their study had high mortality rates $(7 \%$ vs $5.3 \%)$. They reported that $68 \%$ of hospital deaths had a cardiac cause. Bjessmo et $\mathrm{al}^{6}$ found almost $85 \%$ of early deaths had a cardiac cause and speculated that the high incidence of cardiac death was related to perioperative myocardial protection methods. Onorati and colleagues ${ }^{14}$ evaluated myocardial protection methods in patients with ACS and found that off-pump CABG and on-pump CABG with antegrade and retrograde blood cardioplegia resulted in less elevation of troponin I levels than on-pump CABG with isolated antegrade cardioplegia. They suggested that patients with ACS who underwent off-pump CABG seemed to have better outcomes compared with patients who received simple myocardial protection techniques during cardiopulmonary bypass. Recently, Ben-Gal and colleagues ${ }^{15}$ found that off-pump CABG was associated with lower rates of bleeding and nonQ-wave myocardial infarction than on-pump CABG in patients with ACS. Rastan and colleagues ${ }^{7}$ reported that beating heart coronary artery grafting was associated with an improved hospital outcome compared with cardioplegic cardiac arrest in patients with ACS. In the present study, the major cause of operative death in patients with ACS was not low output syndrome ( 1 of 10 patients). We believe that 1 of reasons for this might be because most operations were performed using the off-pump technique. In patients with ongoing myocardial ischemia, off-pump CABG might reduce the myocardial damage by avoidance of reperfusion injury. ${ }^{7,15}$

The use of arterial grafts for myocardial revascularization has been widely accepted because of the clinical advantage of using the left ITA as a bypass conduit. ${ }^{16}$ The use of bilateral ITA grafts has been shown to provide survival and economic benefits compared with the use of a single ITA graft. ${ }^{17}$ Bonacchi and colleagues ${ }^{9,18}$ demonstrated the safety and effectiveness of using bilateral ITA grafts in patients with ACS. Furthermore, they showed the superiority of bilateral ITA grafts compared with single ITA grafts in mid-term and event-free survival in patients with ACS. ${ }^{18}$ However, bilateral ITA grafts are not routinely used on a widespread basis, even in elective patients, for multiple reasons, including increased operative difficulty, increased operating time, and the risk of wound complications. ${ }^{19}$ In the present study, we used bilateral ITA grafts for most patients. Harvesting the bilateral ITA takes longer than the time needed for single ITA. Accordingly, it might be inappropriate to use bilateral ITA for patients with
ACS because it will delay reperfusion in the culprit lesion. However, in the present study, the use of bilateral ITA was not the independent risk factor for operative death (odds ratio, 0.339; 95\% confidence interval, 0.089-1.295; $P=.1137$ ) or the requirement for hemodialysis (odds ratio, $0.727 ; 95 \%$ confidence interval, $0.210-2.0514 ; P=.6150$ ) on univariate analysis. However, the use of bilateral ITA was protective for low output syndrome on univariate analysis (odds ratio, $0.267 ; 95 \%$ confidence interval, 0.107 $0.666 ; P=.0046$ ) and multivariate analysis (odds ratio, $0.244 ; 95 \%$ confidence interval, $0.904-0.963 ; P=.0042$ ). Bonacchi and colleagues ${ }^{20}$ stated that in emergent/urgent myocardial revascularization with careful patient management, it is possible to spend a few minutes more to harvest both ITAs using a skeletonized technique. This is because of the important early and long-term advantages of this conduit, such as early improved flow/reperfusion and freedom from late atherosclerotic disease in patients with UAP. ${ }^{20}$ We believe that bilateral ITA grafts should be used even in patients with ACS because of the long-term survival advantage as long as they are harvested in appropriate time.

In patients undergoing PCI, long-term outcome comparisons between patients with ACS and SAP have had conflicting results. In the Lescol Intervention Prevention Study, the long-term risks of UAP and SAP after PCI were similar in patients with ACS and SAP. ${ }^{21}$ In a subanalysis of the Arterial Revascularization Therapies Study, no significant differences were found in the rates of major adverse cardiac events at 1 year between patients with ACS and SAP. ${ }^{22}$ However, Naidu and colleagues ${ }^{23}$ reported a greater rate of death and of combined death and myocardial infarction for patients with ACS than SAP. In patients with ACS, the role of the global atherosclerotic burden and disease progression after PCI in arteries not undergoing intervention should be considered. ${ }^{23} \mathrm{CABG}$ provides revascularization of most of the epicardial vessels, including the culprit lesion. Successful CABG might, therefore, reduce the likelihood of future ischemic events in patients with ACS. In the present study, no differences were found in the rates of survival or MACCE between patients with ACS and SAP.

In patients with ACS, the urgency for surgery was considered 1 of the risk factors after $\mathrm{CABG}^{24}{ }^{24}$ The European guideline suggests that the benefit from $\mathrm{CABG}$ is greatest when patients can undergo surgery after several days of stabilization. ${ }^{25}$ Conversion from ACS to SAP before CABG would be 1 of the options if patients had stable hemodynamic condition. In the present study, 9 patients were converted from ACS to SAP because of previous PCI. All had hemodynamic stability and favorable coronary anatomy and resulted in no complications after elective CABG.

However, patients with unfavorable anatomy for PCI, PCI failure, diffuse coronary artery disease, hemodynamic 
instability, or impaired left ventricular dysfunction should be considered to perform early CABG. We performed early CABG for those patients with ACS. With this strategy, 10 operative deaths occurred in patients with ACS. All of them had required an emergent operation owing to ongoing ischemia and were not suitable for PCI because of unfavorable anatomy. They had relatively high risk scores as follows: the European System for Cardiac Operative Risk Evaluation II score was $10.1 \pm 12.2$, the Society of Thoracic Surgeons predicted risk score was $10.2 \pm 10.2$, and Synergy between PCI with Taxus and Cardiac Surgery) score was $24.0 \pm 10.2$. It was difficult to determine whether these high-risk patients could have had better outcomes by waiting for conversion from ACS to SAP.

\section{Study Limitations}

Our study had the following limitations. This was a retrospective observational study. The treatment and treatment timing varied according to the practices of the individual physicians and surgeons. Also, the number of patients and the follow-up period of 7 years might not be sufficient to provide definitive results.

\section{CONCLUSIONS}

ACS is an independent predictor of early mortality in patients undergoing CABG. However, the long-term outcomes after surgery were similar between patients with ACS and SAP, once patients had survived the early postoperative period.

The authors thank Ko Bando, MD, for his extensive review and valuable comments.

\section{References}

1. Antman EM, Anbe DT, Armstrong PW, Bates ER, Green LA, Hand M, et al; American College of Cardiology; American Heart Association Task Force on Practice Guidelines; Canadian Cardiovascular Society. ACC/AHA guidelines for the management of patients with ST-elevation myocardial infarction: a report of the American College of Cardiology/American Heart Association Task Force on Practice Guidelines (Committee to Revise the 1999 Guidelines for the Management of Patients with Acute Myocardial Infarction). Circulation. 2004;110: e82-292.

2. Wright RS, Anderson JL, Adams CD, Bridges CR, Casey DE Jr, Ettinger SM, et al; American College of Cardiology Foundation/American Heart Association Task Force on Practice Guidelines. 2011 ACCF/AHA focused update incorporated into the ACC/AHA 2007 Guidelines for the Management of Patients with Unstable Angina/Non-ST-Elevation Myocardial Infarction: a report of the American College of Cardiology Foundation/American Heart Association Task Force on Practice Guidelines developed in collaboration with the American Academy of Family Physicians, Society for Cardiovascular Angiography and Interventions, and the Society of Thoracic Surgeons. J Am Coll Cardiol. 2011;57: e215-367.

3. Elbardissi AW, Aranki SF, Sheng S, O'Brien SM, Greenberg CC, Gammie JS. Trends in isolated coronary artery bypass grafting: an analysis of the Society of Thoracic Surgeons adult cardiac surgery database. J Thorac Cardiovasc Surg. 2012;143:273-81.

4. Taggart DP, Thomas B. Ferguson Lecture: coronary artery bypass grafting is still the best treatment for multivessel and left main disease, but patients need to know. Ann Thorac Surg. 2006;82:1966-75.
5. Louagie YA, Jamart J, Buche M, Eucher PM, Schoevaerdts D, Collard E, et al. Operation for unstable angina pectoris: factors influencing adverse in-hospital outcome. Ann Thorac Surg. 1995;59:1141-9.

6. Bjessmo S, Hammar N, Sandberg E, Ivert T. Reduced risk of coronary artery bypass surgery for unstable angina during a 6-year period. Eur J Cardiothorac Surg. 2000; 18:388-92.

7. Rastan AJ, Eckenstein JI, Hentschel B, Funkat AK, Gummert JF, Doll N, et al. Emergency coronary artery bypass graft surgery for acute coronary syndrome: beating heart versus conventional cardioplegic cardiac arrest strategies. Circulation. 2006;114(1 suppl):I477-85.

8. Bjessmo S. Increased rehospitalization rate after coronary bypass operation for acute coronary syndrome: a prospective study in 200 patients. Ann Thorac Surg. 2009;88:1148-52.

9. Bonacchi M, Prifti E, Giunti G, Frati G, Sani G. Urgent surgical revascularization of unstable angina: influence of double mammary arteries. Eur J Cardiothorac Surg. 2001;20:747-54.

10. Fukui T, Takanashi S, Hosoda Y, Suehiro S. Early and midterm results of offpump coronary artery bypass grafting. Ann Thorac Surg. 2007;83:115-9.

11. Fukui T, Tabata M, Taguri M, Manabe S, Morita S, Takanashi S. Extensive reconstruction of the left anterior descending coronary artery with an internal thoracic artery graft. Ann Thorac Surg. 2011;91:445-51.

12. Ben-Gal Y, Moses JW, Mehran R, Lansky AJ, Weisz G, Nikolsky E, et al. Surgical versus percutaneous revascularization for multivessel disease in patients with acute coronary syndromes: analysis from the ACUITY (Acute Catheterization and Urgent Intervention Triage Strategy) trial. JACC Cardiovasc Interv. 2010; 3:1059-67.

13. Kaiser GC, Schaff HV, Killip T. Myocardial revascularization for unstable angina pectoris. Circulation. 1989;79:I60-7.

14. Onorati F, De Feo M, Mastroroberto P, di Virgilio A, Esposito A, Polistena M, et al. Unstable angina and non-ST segment elevation: surgical revascularization with different strategies. Eur J Cardiothorac Surg. 2005;27:1043-50.

15. Ben-Gal Y, Stone GW, Smith CR, Williams MR, Weisz G, Stewart AS, et al. Onpump versus off-pump surgical revascularization in patients with acute coronary syndromes: analysis from the Acute Catheterization and Urgent Intervention Triage Strategy trial. J Thorac Cardiovasc Surg. 2011;142:e33-9.

16. Cameron A, Davis KB, Green G, Schaff HV. Coronary bypass surgery with internal-thoracic-artery grafts-effects on survival over a 15 -year period. $N$ Engl J Med. 1996;334:216-9.

17. Taggart DP, D'Amico R, Altman DG. Effect of arterial revascularization on survival: a systematic review of studies comparing bilateral and single internal mammary arteries. Lancet. 2001;358:870-5.

18. Bonacchi M, Prifti E, Maiani M, Giunti G, Leacche M. Skeletonized bilateral internal mammary arteries for non-elective surgical revascularization in unstable angina. Eur J Cardiothorac Surg. 2005;28:120-6.

19. Tabata M, Grab JD, Khalpey Z, Edwards FH, O’Brien SM, Cohn LH, et al. Prevalence and variability of internal mammary artery graft use in contemporary multivessel coronary artery bypass graft surgery: analysis of the Society of Thoracic Surgeons National Cardiac Database. Circulation. 2009;120:935-40.

20. Bonacchi M, Maiani M, Leacche L. Why skeletonized BIMA for unstable angina? Eur J Cardiothorac Surg. 2005;28:781.

21. Lee CH, de Feyter P, Serruys PW, Saia F, Lemos PA, Goedhart D, et al. Beneficial effects of fluvastatin following percutaneous coronary intervention in patient with unstable and stable angina: results from the Lescol Intervention Prevention Study (LIPS). Heart. 2004;90:1156-61.

22. De Feyter PJ, Serruys PW, Unger F, Beyar R, de Valk V, Milo S, et al. Bypass surgery versus stenting for the treatment of multivessel disease in patients with unstable angina compared with stable angina. Circulation. 2002;105:2367-72.

23. Naidu SS, Polin GM, Selzer F, Laskey WK, Jacobs AK, Williams DO, et al. Outcome of percutaneous coronary intervention in unstable angina pectoris versus stable angina pectoris in two different time periods. Am J Cardiol. 2006;98: 447-52.

24. Curtis JJ, Walls JT, Salam NH, Boley TM, Nawarawong W, Schmaltz RA, et al. Impact of unstable angina on operative mortality with coronary revascularization at varying time intervals after myocardial infarction. J Thorac Cardiovasc Surg. 1991;102:867-73.

25. Kolh P, Wijns W, Danchin N, Di Mario C, Falk V, Folliguet T, et al. Guidelines on myocardial revascularization. Task Force on Myocardial Revascularization of the European Society of Cardiology (ESC) and the European Association for CardioThoracic Surgery (EACTS); European Association for Percutaneous Cardiovascular Interventions (EAPCI). Eur J Cardiothorac Surg. 2010;38:S1-52. 


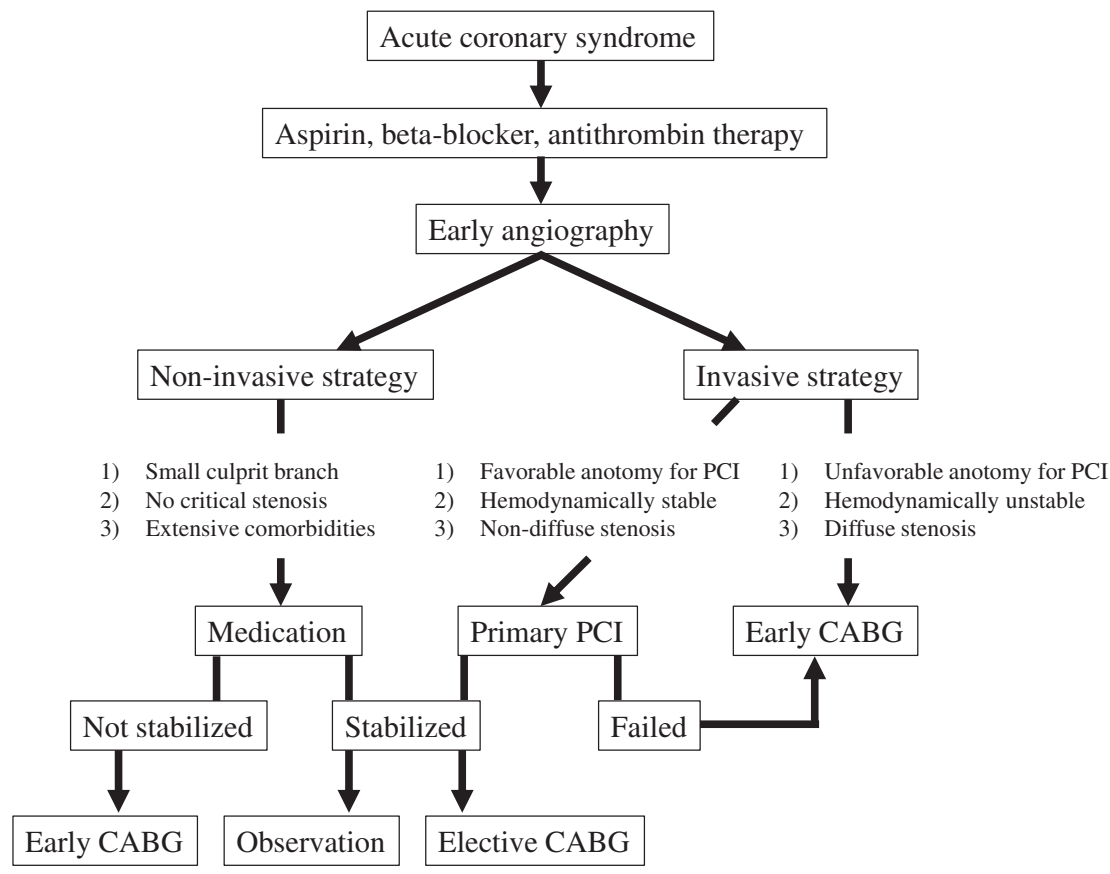

FIGURE E1. Our strategy of coronary artery bypass grafting $(C A B G)$ for acute coronary syndrome $(A C S)$. STEMI, ST-segment elevation myocardial infarction; NSTEMI, non-STEMI; UAP, unstable angina pectoris; $P C I$, percutaneous coronary intervention.

TABLE E1. Preoperative characteristics of study patients and patients with STEMI

\begin{tabular}{lccr}
\hline \multicolumn{1}{c}{ Variable } & $\begin{array}{c}\text { Study patients } \\
(\mathbf{n}=\mathbf{1 2 3 3})\end{array}$ & $\begin{array}{c}\text { Patients with STEMI } \\
(\mathbf{n}=\mathbf{7 0})\end{array}$ & $\begin{array}{c}\boldsymbol{P} \\
\text { value }\end{array}$ \\
\hline Age & $68.0 \pm 10.4$ & $69.3 \pm 11.1$ & .2901 \\
Female gender & $237(19.2)$ & $12(17.1)$ & .7840 \\
BSA (m $\left.{ }^{2}\right)$ & $1.7 \pm 0.2$ & $1.6 \pm 0.2$ & .3667 \\
EF $(\%)$ & $56.3 \pm 11.5$ & $44.1 \pm 12.4$ & $<.0001$ \\
Previous MI & $551(44.7)$ & $23(32.9)$ & .0694 \\
Diseased vessel & $2.8 \pm 0.5$ & $2.8 \pm 0.4$ & .3518 \\
Left main disease & $423(34.3)$ & $27(38.6)$ & .5479 \\
Previous PCI & $353(28.6)$ & $26(37.1)$ & .1644 \\
CHF & $153(12.4)$ & $27(38.6)$ & $<.0001$ \\
Hypertension & $840(68.1)$ & $41(58.6)$ & .1259 \\
Diabetes mellitus & $579(47.0)$ & $34(48.6)$ & .8867 \\
Hyperlipidemia & $781(63.3)$ & $33(47.1)$ & .0094 \\
Smoking & $734(59.5)$ & $39(55.7)$ & .6120 \\
PVD & $99(8.0)$ & $6(8.6)$ & $>.9999$ \\
Previous stroke & $130(10.5)$ & $10(14.3)$ & .4323 \\
Creatinine (mg/dL) & $1.2 \pm 1.5$ & $1.0 \pm 0.5$ & .2836 \\
COPD & $45(3.6)$ & $2(2.9)$ & $>.9999$ \\
Atrial fibrillation & $59(4.8)$ & $5(7.1)$ & .3856 \\
\hline D. &
\end{tabular}

Data presented as mean \pm standard deviation or numbers (percentages). BSA, Body surface area; $C H F$, congestive heart failure; $C O P D$, chronic obstructive pulmonary disease; $E F$, ejection fraction; $M I$, myocardial infarction; $P C I$, percutaneous coronary intervention; $P V D$, peripheral vascular disease; STEMI, ST-segment elevation myocardial infarction.
TABLE E2. Operative and postoperative data of study patients and patients with STEMI

\begin{tabular}{lccr}
\hline \multicolumn{1}{c}{ Variable } & $\begin{array}{c}\text { Study patients } \\
(\mathbf{n}=\mathbf{1 2 3 3})\end{array}$ & $\begin{array}{c}\text { Patients with } \\
\text { STEMI }(\mathbf{n}=\mathbf{7 0})\end{array}$ & $\begin{array}{c}\boldsymbol{P} \\
\text { value }\end{array}$ \\
\hline Anastomoses & $4.1 \pm 1.2$ & $4.0 \pm 1.2$ & .3942 \\
ITA use & $1229(99.7)$ & $69(98.6)$ & .2416 \\
Bilateral ITA use & $1092(88.6)$ & $55(78.6)$ & .0205 \\
Extensive reconstruction & $282(22.9)$ & $14(20.0)$ & .6809 \\
$\quad$ of LAD & & & \\
Off-pump procedure & $1192(96.7)$ & $64(91.4)$ & .0499 \\
Operation time (min) & $276.8 \pm 62.4$ & $261.9 \pm 50.6$ & .0495 \\
Transfusion & $407(33.0)$ & $38(54.3)$ & .0004 \\
Intubation (h) & $9.2 \pm 13.5$ & $34.2 \pm 105.4$ & $<.0001$ \\
ICU stay (d) & $1.7 \pm 6.3$ & $5.5 \pm 16.9$ & $<.0001$ \\
Operative death & $11(0.9)$ & 0 & $>.9999$ \\
Re-exploration due to & $14(1.1)$ & $1(1.4)$ & .5652 \\
$\quad$ bleeding & & & \\
Low output syndrome & $22(1.8)$ & $6(8.6)$ & .0007 \\
Perioperative MI & $12(1.0)$ & 0 & $>.9999$ \\
Severe ventricular arrhythmia & $9(0.7)$ & $5(7.1)$ & .0008 \\
Required hemodialysis & $20(1.6)$ & $2(2.9)$ & .3330 \\
Stroke & $17(1.4)$ & $4(5.7)$ & .0228 \\
Mediastinitis & $11(0.9)$ & $1(1.4)$ & .4863 \\
\hline Da presen
\end{tabular}

Data presented as mean \pm standard deviation or numbers (percentages). ICU, Intensive care unit; ITA, internal thoracic artery; $L A D$, left anterior descending artery; $M I$, myocardial infarction; STEMI, ST-segment elevation myocardial infarction. 